IFN Working Paper No. 998, 2013

Strategic Interaction vs. Regulatory Compliance among Regulated Utilities: The Swedish Water Sector

\author{
Erik Lundin
}




\title{
Strategic Interaction vs. Regulatory Compliance among Regulated Utilities: The Swedish Water Sector*
}

\author{
Erik Lundin ${ }^{\dagger}$
}

December 17, 2013

\begin{abstract}
This study provides the first empirical test of strategic interactions in the pricing decisions of regulated utilities. Since publicly owned water utilities in Sweden are governed by a cost-of-service regulation, prices in neighboring municipalities should not affect the own price other than through spatially correlated cost factors. In contrast, spatial dependence is pronounced. This behavior can be explained in terms of an informal yardstick competition: When consumers use neighboring utilities' prices as benchmarks for costs or as behaviorally based reference prices, utilities will face the risk of consumer complaints and successive regulatory reviews if deviating too much from neighbors' prices.
\end{abstract}

Keywords: yardstick competition; spatial econometrics; public economics; utilities

JEL classification: D4, L1, L5, L9

\footnotetext{
*I am grateful for comments from Richard Friberg and Pär Holmberg. This research was financed within the IFN research program "The Economics of Electricity Markets".

${ }^{\dagger}$ Research Institute of Industrial Economics (IFN). P.O. Box 55665, SE-102 15 Stockholm, Sweden. Phone: +46 7075258 47. E-mail: erik.lundin@ifn.se; Stockholm School of Economics, Sveavägen 65 , Stockholm, Sweden.
} 


\section{Introduction}

Ever since Tiebout (1956) pointed out that citizens evaluate the policies of their local governments in relation to the policies of other jurisdictions, the interdependence in policy decisions among local governments has been a major interest in public economics. Especially, the focus has been on tax setting and the provision of public services; see e.g. Brueckner (2003) for an overview. This paper extends the existing literature by examining strategic interactions in the pricing decisions of regulated utilities. It also adds to the regulatory literature by noting that yardstick competition may arise also in regulated industries that are not subject to a formal yardstick regulation. In this paper, we examine the pricing decisions of almost all Swedish water utilities over 2002-2012. Since publicly owned water utilities in Sweden are governed by a cost-of-service (" $\mathrm{c}-\mathrm{O}-\mathrm{S}$ ") regulation, prices in neighboring municipalities should not affect the own price other than through spatially correlated cost factors. In contrast, spatial dependence is pronounced.

The basic setup in a model of yardstick competition typically involves a regulator and a number of local monopolists with identical cost functions; for a seminal contribution see Shleifer (1985). The cost function is unknown to the regulator. For any given firm, the price that the firm gets is equal to the average self-reported cost of the other firms. If a firm reduces costs when its twin firms do not, it profits; if it fails to do reduce costs when other firms do, it incurs a loss. Thus, firms are incentivized to achieve productive efficiency. But if the citizens of a jurisdiction evaluate the performance of the local policy makers by comparing with the surrounding jurisdictions this can also generate a type of yardstick competition even in absence of a central regulator. A presumption is then that citizens can punish the firm, either by lobbying for lower prices or the replacement of managers, or by voting the local policy maker out of office.

Informal yardstick competition is not unknown in public economics. For instance, Besley and Case (1995) have adapted Schleifer's original model to describe a system with asymmetric information between voters and politicians. The latter are assumed to know more about the cost of providing public services than the former. Consonant with the large literature on multiagent incentive schemes (see e.g. Holmstrom (1982)) they show that it makes sense for voters to appraise their incumbent's relative performance if neighboring jurisdictions face correlated cost shocks. Since tax rates are a proxy for the price of public production, citizens will evaluate the performance of their local policy makers by comparing their tax rates with those of neighboring jurisdictions. This induces local policy makers to mimic their neighbors' tax policies in order not to look bad in comparison and be voted out of office.

Geys (2006) notes that even in absence of correlated cost shocks, informal yardstick competition may arise if neighbors' tax rates serve as behaviorally based reference prices by which the own tax rate is compared, thereby generating the so-called trans- 
action utility introduced by Thaler (1985). The most important factor for determining the reference price is fairness, and the transaction utility for buying a certain good is positive if the realized price is less than the reference price. Thus, if citizens believe that it is fair that they pay the same tax as their neighbors, the transaction utility will depend on the difference between the own- and neighbors' taxes.

Is informal yardstick competition also at play in utility markets? Theoretically it should be easier for citizens to compare the performance of individual utilities than the total production of public services. First, utilities produce comparatively homogenous goods (e.g. electricity distribution, water provision, district heating and telecommunications). By contrast, a bundle of public services (or even a single one) may vary a lot in quality. Therefore, public services are harder to compare both in relation to quality and fairness principles. Further, the tax rate is merely an approximation of the price of public services, while a well-defined price for a utility service serves as a natural benchmark for efficiency. Recently, some studies have found evidence of yardstick competition in the pricing decisions of unregulated utilities (see Klien (2012); Söderberg and Tanaka (2012)). However, to the best of my knowledge, this is the first study to observe yardstick competition in a market subject to a co-s regulation. Given that utilities comply with the regulatory framework there is no scope for such behavior. On the other hand, if regulatory monitoring is loose citizens may use neighboring utilities' prices as benchmarks for good performance or as reference prices, inducing utilities to mimic the prices of their neighbors.

Arguably, the Swedish water sector provides an excellent testing ground for the existence of informal yardstick competition among regulated utilities. Almost all water services have for a long time been provided by publicly owned utilities, independently organized by each municipality. They are regulated by a loosely monitored c-o-s regulation, and Haraldsson (2013) notes that $45 \%$ of the municipalities do not even fulfill basic legal accounting requirements. Many of the utilities also belong to publicly owned energy conglomerates, facilitating cross-subsidization between divisions. This should make leeway for a fair degree of arbitrariness in the pricing decisions. As of 2012, price differences were substantial, ranging from 3000 to 10000 SEK $^{1}$ per year for a regular household. Many municipalities have price trends that follow closely the trend of their neighbors, for no apparent reason. As an illustrative example, figure 1 shows the price trends in two neighboring municipalities, Ockelbo and Sandviken.

[Figure 1 about here]

In both municipalities, prices have increased by $120 \%$ during the last decade, compared to the industry average of $42 \%$. The price increase in Ockelbo could largely be explained by high investments, which were on average 1000 SEK per year and resident for the years when data on investments were available, compared to the industry average of 600 SEK per year. By comparison, the neighboring municipality

\footnotetext{
${ }^{1} 1 \mathrm{SEK} \approx € 0.11$ in 2012.
} 
Sandviken has invested only 300 SEK per year, i.e. well below the industry average. Sandviken's water utility is both physically and organizationally isolated from every other water system in the region. Further, Sandviken's water utilities are part of a publicly owned energy conglomerate, which should facilitate cross-subsidization. This raises concerns whether Sandviken raised its price in response to the price increases in Ockelbo, and if so, whether such pricing strategies have been adopted on a systematic basis.

Using a fixed effects spatial durbin model with data from almost all Swedish municipalities during 2002-2012, I estimate the elasticity of the own- relative to neighbors' average price to be 0.14 . Results from cross-sectional data using even more detailed information about the technical characteristics of the utilities suggest an even higher degree of spatial dependence. However, due to the absence of fixed effects these estimates should be interpreted with care. Further, spatial dependence is not attenuated in municipalities with a politically stable electorate, suggesting that managers' decisions rather than political influence is the main driving mechanism behind the result.

The rest of this paper is structured as follows: Section two reviews the related literature and discusses some theoretical predictions, section three describes the institutional framework and the data, section four presents the model, section five presents the results, section six provides a further discussion on the underlying mechanisms and implications for efficiency, and section seven concludes.

\section{Related literature}

What predictions can we make based on previous literature? The strategic interactions between local governments can be divided into two broad categories: "spillover models" and "resource flow models". ${ }^{2}$ In the spillover framework each jurisdiction chooses the level of a decision variable, but the jurisdiction is also affected by the decision chosen elsewhere (without triggering any physical flows of goods, residents or capital across borders). The resource flow model, on the other hand, recognizes that policy makers adjust their policy decisions in order to attract certain residents or capital to the jurisdiction, or to attract cross-border shopping.

Starting with the spillover framework, yardstick competition is an example of such a model in which information spillovers help citizens to judge the performance of their government. The studies that are most closely related to the present one are Klien (2012) and Söderberg and Tanaka (2012). ${ }^{3}$ Klien investigates yardstick

\footnotetext{
${ }^{2}$ For a more thorough review of these models, see e.g. Brueckner (2003); Revelli (2005).

${ }^{3} \mathrm{As}$ discussed in the introduction, these markets are not subject to a c-o-s regulation. Still, it should be noted that in none of these markets utilities are completely free to set their own prices. The Austrian utilities are not allowed to set a price that exceeds twice the total cost of production (i.e. twice as high markup as for the Swedish utilities). However, Klien (2012) notes that "...price setting appears very ad-hoc and discretionary..." (p.6) and that "... the Austrian water sector...is characterized by the absence of a regulator..." (p.6) Similarly, the Swedish market for district heating
} 
competition among Austrian water utilities using a panel data set covering 20002009. He finds some evidence of yardstick competition, but since the utilities are free to set their own price, nothing can be said about the utilities' regulatory compliance. Söderberg and Tanaka develop a general model to measure spatial price heterogeneity as a source of regulatory threat in locally monopolistic sectors. The model is then applied to the unregulated market for Swedish district heating using a cross-sectional dataset from 2004. Results show that only investor-owned utilities mimic the prices of their neighbors, which is explained by the fact that publicly owned utilities set prices to maximize social welfare. In another study, Bivand and Szymanski (1997) find spatial dependence in the cost of public procurement contracts for garbage collection in the UK. However, their setup is rather different than ours since the agents are the garbage contractors (and not the local government) and the principals are the local government (and not the citizens). Second, the contracts are explicitly based on comparisons of performance against neighboring regions. Rather than an example of informal yardstick competition, this study is best interpreted in the light of Green and Stokey (1983), who noted that it is sometimes optimal (from the principal's point of view) to make payments contingent on the performance of other agents when agents are risk-averse and face correlated cost shocks.

A related strand of literature examines yardstick competition in the provision of social services and tax rates. For instance, Sole Olle (2003) finds evidence of yardstick competition in the tax rates among Spanish municipalities. He also finds a positive relation between tax mimicking and a low electoral margin, suggesting that politicians facing a higher risk of being voted out of office are relatively more prone to mimic their neighbors. In another study, Revelli (2006) finds evidence of yardstick competition in the social service provision of UK local authorities. After the introduction of a national evaluation program spatial dependence in the expenditures on personal services was attenuated, in line with the hypothesis that the decreased importance of local information-spillovers reduced the scope for local performance comparisons. Other studies try to instead examine yardstick competition in the productive efficiency of local governments directly. For instance, Revelli and Tovmo (2007) find evidence of yardstick competition in the production efficiency of Norwegian local governments. Geys (2006) does the same for Flemish local governments, and uses the ratio of tax revenues to the quantity of locally provided public goods as the decision variable. With respect to the decision variable, the two latter studies lie closest to the present study since water prices are expressed in terms of price over quantity directly.

Moving over to the resource flow framework, one of the earliest studies to fall under this category is Mintz and Tulkens (1986), who develop a theoretical model in which an origin-based commodity tax is levied by each region. Citizens then decide whether to buy the commodity from the domestic- or nondomestic market, and the

is in theory regulated by a specific district heating law. But this regulation does not cover price setting per se, so the market may be characterized as unregulated, as argued by e.g. Konkurrensverket (2013). 
tax revenues are used to finance a local public good. Spatial dependence in tax rates is obtained as a noncooperative Nash equilibrium. The theory has been extended to incorporate different types of regional heterogeneity, see e.g. Kanbur and Keen (1993) for an analysis when regions differ in size. The theoretical predictions of these models have been tested by e.g. Jacobs, Ligthart, and Vrijburg (2010), who find strong evidence for consumption tax competition using a U.S. data set covering the years 1977-2003. For a study on the competition for capital, see for instance Buettner (2001) who study of spatial dependence in local business taxes in Germany. Models of welfare competition also fall under the resource flow framework. In such models, the altruistic rich provide a transfer to the poor, which triggers migration of poor citizens between jurisdictions. Figlio, Kolpin, and Reid (1999) provide an application on U.S. data covering 1983-1994, finding substantial empirical evidence of welfare competition.

For fundamental insights in the strategic interactions between the regulator and the firm under asymmetric information, see Laffont and Tirole (1993). For instance, they describe how a c-o-s regulation may lead to overinvestment, lack of incentives to reduce costs and subsequent distorted prices.

\section{Institutional background and description of the data}

The Swedish public sector is organized into three layers of government: National, county and municipal. The local units are responsible for the provision of important welfare services; the Swedish municipalities supply education, child care, social assistance and care for the elderly, while medical care and public transport are organized at the county level. Swedish municipalities have the constitutional right of self-government. The degree of autonomy refers both to the right to decide on the provision of local public services and their right to set the local income tax rate. This is also their main source of income.

For a long time, the municipalities have also been responsible for the provision of water- and sewage services, electricity distribution and district heating. Due to liberalization in the 1990 's, the electricity distribution- and district heating sectors are now a mix of public and private ownership, while the water sector has remained regulated. The water sector also has the longest history of public ownership. Already in the mid-1800's, after the outbreaks of several cholera epidemics, local governments started to invest in water pipes to be able to provide clean water to the citizens. The development during the last century was rapid, and water consumption increased exponentially until the late 1960's (Svenskt-Vatten, 2005). At present there are 1700 publicly owned waterworks in Sweden. The Municipal Act restricts municipalities from operating within the geographical area of other municipalities. Due to this restriction it has been difficult for municipalities to cooperate without forming local government federations or jointly owned companies. However, in the new Water and 
Sewage Act which came into force 2006, water utilities are exempted from this rule (SCS, 2013). This means that since 2006 a municipality or a municipally owned company can participate in a call for tender for the provision of water and sewage services in other municipalities.

Due to its feature as a natural monopoly, water provision is regulated by law, stating that "The fees must not exceed what is necessary to cover the costs necessary to organize and operate the plants" (excerpt from the Water and Sewage Act, freely translated from Swedish). A noteworthy addendum is found in $29 \S$, in which the legislator distinguishes between connection fees and user fees. The connection fees should be set to cover the costs of connecting a new property to the system, and the user fees should be set to cover the operating costs of the water facilities. The present study will focus on the user fees, although in theory one could instead have chosen to study the connection fees. There also exist a theoretical possibility of subsidizing parts of the investments in the utilities with tax revenues. However, in there are no accounts that this exercise is There is no official regulatory supervisor, but the Swedish Water Supply and Sewage Tribunal adjudicate legal disputes relating to water supply and sewerage. ${ }^{4}$

\section{Data}

The data set consists of 288 Swedish municipalities during 2002-2012. ${ }^{5}$ Table 1 shows descriptive statistics for each variable, and table A1 shows detailed descriptions of the variables including data sources.

\section{[Table 1 about here]}

The main variable of interest is "Water price", which is defined as the total cost for water- and sewerage services paid by a typical single-family house consuming 150 $m^{3}$ water each year. The water fee is constructed as a two-part tariff. For the whole sample, the mean share of the fixed price is $43 \%$ with a standard deviation of $11 \%$. Figure 2 shows a map illustrating the dependent variable for the year 2004, and figure A3 shows a histogram of the dependent variable for the whole sample.

[Figure 2 about here]

Upon examination of figure 2, it appears that regions with a high population density enjoy lower prices than other regions. This is not surprising, and returns to

\footnotetext{
${ }^{4}$ Complaints occur on a relatively frequent basis, and there are several cases where residential consumers have initiated complaints that have led to price revisions (SWSST, 2013). In at least one recent case, customers have based their complaint on the difference in price compared to a neighboring region. The Water Supply and Sewage Tribunal found that the price discrimination was illegal, and prices were revised. Specifically, this case was concerned with price discrimination within a municipality. Municipalities are only allowed to price discriminate between geographical regions if it can be justified by differences in the costs of water provision.

${ }^{5}$ In total there are 290 municipalities. Huddinge municipality has been excluded due to missing data on water prices, and Knivsta municipality has been excluded since it was formed in 2003 (this area was earlier a part of Uppsala municipality).
} 
network density in water provision has been discussed by e.g. Mizutani and Urakami (2001). Moran's $I^{6}$ for the dependent variable is 0.24 (the raw correlation between the own- and neighbors' price is 0.46).

The independent variables can be divided into two groups. The first group contains cost factors. The included cost factors are the number of single-family houses, number of apartment houses, population, the average wage for a public servant, the number of purification plants, pipeline length, capacity utilization, number of connected residents, and investments. The last six of these variables are only available for the year 2004. Therefore the fixed-effects model is complemented by cross-sectional estimates, including the same spatial models as for the full sample. The reason why I have included the average wage for a public servant and not the accounting cost of labor is that the true cost function would be distorted if some utilities pay wages above market rates or hire more workers than needed.

The second group contains variables that in theory should not influence prices if utilities comply with the regulatory framework. These variables could potentially influence the price of water if rents are transferable between the utility and the municipal budget. Extraordinary income (net of extraordinary costs) could prevent politicians from raising prices, so the expected sign is negative. Government grants constitute an extra income for the municipality, so the expected sign is negative. The expected sign for the municipality surplus is negative, since economic problems could be partly compensated for by raising prices. The expected sign for the tax rate is ambiguous, since revenues from the utilities could be both complements and substitutes to tax revenues. I have also included a dummy variable indicating the political affiliation of the ruling coalition. The expected sign is ambiguous, but since the estimated coefficient is small and insignificant throughout all specifications I will not comment further on the potential effects of political affiliations.

\section{The model}

\section{Panel data estimates}

Even though the covariates are chosen to reflect the cost function as well as other potential determinants of the water price, we cannot exclude the possibility of spatially correlated omitted variables. Therefore I estimate the spatially autoregressive model ("SAR"), the spatial error model ("SEM"), as well as the spatially mixed model. The mixed model allows for spatial lags in both the dependent variable and the error term. I also estimate the spatial durbin model, which includes a spatial lag in the dependent as well as the independent variables. This model can also be motivated by the presence of omitted variables, which is discussed in more detail below. After estimation, likelihood ratio tests are used to find out which data generation process

\footnotetext{
${ }^{6}$ Moran's $I$ is a measure of spatial autocorrelation, see Moran (1950) for a technical discussion.
} 
that provides the best description of the data. Formally, the models can be expressed as:

$$
\begin{gathered}
p_{i t}=\alpha+\rho \mathbf{W}_{i} \boldsymbol{p}_{t}+\mathbf{X}_{i t} \boldsymbol{\beta}+\mathbf{y}_{\mathrm{t}}+m_{i}+u_{i t} \\
p_{i t}=\alpha+\mathbf{X}_{i t} \boldsymbol{\beta}+\mathbf{y}_{t}+m_{i}+\lambda \mathbf{W}_{i} \eta_{i t}+u_{i t} \\
p_{i t}=\alpha+\rho \mathbf{W}_{i} \boldsymbol{p}_{t}+\mathbf{X}_{i t} \boldsymbol{\beta}+\mathbf{y}_{t}+m_{i}+\lambda \mathbf{W}_{i} \eta_{i t}+u_{i t} \\
p_{i t}=\alpha+\rho \mathbf{W}_{i} \boldsymbol{p}_{t}+\mathbf{X}_{i t} \boldsymbol{\beta}+\mathbf{W}_{i} \mathbf{X}_{i t} \boldsymbol{\gamma}+\mathbf{y}_{t}+m_{i}+u_{i t} \quad \text { (Mixed) }
\end{gathered}
$$

Where $p_{i t}$ is the water price in municipality $i$ in year $t$, and $\alpha$ is a constant. The coefficient of interest is $\rho$, which determines the spatial dependence in the water price. $\quad \mathbf{W}_{i}$ is a municipality-specific vector of spatial weights; $\mathbf{X}_{i t}$ is a vector of time-variant covariates with its corresponding coefficient vector $\boldsymbol{\beta} ; \mathrm{y}_{\mathrm{t}}$ and $m_{i}$ are time- and municipality fixed effects, and $u_{i t}$ is the idiosyncratic error. The coefficient $\lambda$ determines the spatial dependence in the error term $\left(\eta_{i t}\right.$ is the spatially correlated component of the error term in the SEM and the mixed model). The coefficient vector $\gamma$ determines the spatial dependence in the covariates. Note that the notation is similar across models, even though the models are different. This is common practice in spatial econometrics, and the notation follows that of LeSage and Pace (2009).

The entries in the normalized symmetric spatial weights matrix $\mathbf{W}$ are:

$$
w_{i j}= \begin{cases}\frac{1}{d_{i j}} & \text { If } j \text { is a neighbor of } i \\ 0 & \text { Otherwise }\end{cases}
$$

Where $d_{i j}$ is the normalized distance between municipality $i$ and $j$. Normalization implies that all rows sum to one. This means that even in regions where municipalities' areas are large, the impact of neighbors' prices is assumed to be of the same magnitude as for regions where municipalities' areas are small. Distance is calculated based on the coordinates of the municipal office in each municipality, which is usually located in the most densely populated area. For each municipality, neighbors are defined as the ten closest municipalities. This is the maximum number of municipalities that share borders with any single municipality. However, it is impossible to know exactly where the appropriate cutoff point should be. Therefore, robustness test are conducted where the number of neighbors range between five and fifteen.

Since $\mathrm{W}$ is symmetric, OLS estimates will generally be biased upwards due to a mechanical simultaneity bias (for a formal proof, see Azomahou and Lahatte (2000)). Therefore a maximum likelihood approach is used, and technical details of the es- 
timation procedure are provided in LeSage and Pace (2009). ${ }^{7}$ Standard errors are clustered by municipality. All variables expect for the dummy variables have been logged.

Anselin (1980) shows that the durbin model can eliminate omitted variable bias in $\hat{\rho}$ (i.e. the spatial lag of the dependent variable). On the other hand, it produces biased coefficients for the covariates. Therefore, it should primarily be used when the coefficient of interest is $\hat{\rho}$. An assumption is then that the omitted variables have to follow roughly the same spatial structure as the included covariates. This is different than the SAC model, which makes no assumption about the spatial structure of the omitted variable other than that they are responsible for any (linear) spatial correlation in the error term. If the covariates do not make a material contribution towards explaining the variation in the dependent variable, the SAC model suffers from identification issues. LeSage and Pace (2009) therefore argue that the durbin model should be used as a general benchmark, and then use likelihood ratio tests to compare it to other spatial models.

However, the durbin model is no complete fix for omitted variable bias. What about the existence of omitted variables that have a higher degree of spatial correlation than the included variables? For example, the availability of water could constitute such a cost shock. If the water reserve gets contaminated in one location, it should be bound to be so also in nearby locations. Further, a fair amount of nearby utilities are operated by the same company, which also should increase the presence of highly spatially correlated cost shocks. Therefore, two additional robustness checks are conducted. First, I estimate the models excluding all municipalities subject to cross-border ownership or joint operation. This removes $30 \%$ of the sample. Second, I estimate the SAR model with an instrumental-variables approach by using neighbors ' past prices (i.e. the first time-lag) as an instrument for neighbors' current prices. The exclusion restriction is then that any correlation between the own price and neighbors' past prices must go through neighbors' current prices. Given the exclusion restriction, $\hat{\rho}$ is unbiased.

The covariates can be divided in two main categories. One category contains cost factors, and the other group contains variables that in theory should not influence prices given that utilities comply with the regulatory framework. Therefore, I also estimate the main specification without the variables belonging to the second category, to see whether results differ.

Lastly, I test whether price mimicking is attenuated when incumbent politicians face a small risk of losing or gaining political influence. To do this, I estimate the main specification removing municipalities where the ruling coalition has received on average $50 \pm 3 \%$ of the votes in the elections that have been taking place during 2002$2012 .{ }^{8}$ This removes $30 \%$ of the original sample. The identification strategy is not

\footnotetext{
${ }^{7}$ The estimator has been implemented using Stata's xsmle command, which is described in detail by Belotti, Hughes, and Mortari (2013) .

${ }^{8}$ In total there were three elections; 2002, 2006 and 2010. All municipalities carry out elections
} 
without hurdles, mainly since coalitions of local governments are often formed after taking election results into account. Unlike in Swedish national politics, it is not uncommon that coalitions are formed across the traditional left-right wing scale, and the average number of parties in the ruling coalition is three. Still, the test should provide a rough idea of whether price mimicking is driven by municipalities in which the ruling coalition is sensitive to changes in voter support.

\section{Cross-sectional estimates}

For the cross-sectional data to provide valid estimates, it is necessary that the covariates capture all cost factors, including the permanent ones. Therefore, these estimates should be regarded only as supplements to the panel estimates. Still, it is of interest to see how much of the variation in prices that can be explained by the extended set of cost factors alone. In these estimates, I have only included variables that belong to the true cost function. This also minimizes risks of over-specification, since the total number of observation in this sample is only 243. For simplicity, I assume a Cobb-Douglas cost function. ${ }^{9}$

The estimation technique is identical to the panel estimates except for the IVestimate, since time-lagged variables rely on panel data. Instead, I employ the generalized spatial two-stage least squares estimator for cross-sectional models proposed by Kelejian and Prucha (1998). This estimator uses information from all exogenous variables and constructs an instrument matrix from their spatial lags. The exogeneity assumption is here that any correlation between neighbors' characteristics (conditional on the own characteristics) and the own price must go through neighbors' price. $^{10}$

A robustness check is conducted by including only those municipalities that did not engage in any water trading during 2004. This choice is motivated by the fact that these networks should be disconnected from all other water systems, minimizing the risk of cost-spillovers. These municipalities comprise $56 \%$ of the total sample (i.e. 138 municipalities). ${ }^{11}$

simultaneously. Since there are no term limits, it is not possible to approximate the importance of voter support with the presence of binding term limits. Data on electroral support has been downloaded from SKL (2013).

${ }^{9}$ Possibly a translog specification would have been preferred, but combined with the relatively few amount of observations this could cause over-specification problems.

${ }^{10}$ The estimator has been implemented using Stata's spreg command, which is described in detail by Drukker, Prucha, and Raciborski (2013).

${ }^{11} \mathrm{I}$ also conducted a robustness test by removing both the municipalities that engaged in water trading and the municipalities that were subject to cross-border ownership or joint operation. These municipalities comprise $44 \%$ of the total sample (138 municipalities). There were only marginal changes in the magnitude and precision of $\hat{\rho}$, except for the mixed model where both $\hat{\rho}$ and $\hat{\lambda}$ were insignificant. Full estimation results are available on request. 


\section{Results}

\section{Results from the panel estimates}

Results from the main specification are presented in table 2 .

[Table 2 about here]

In all maximum likelihood estimations, $\hat{\rho}$ (i.e. the spatial lag of the dependent variable) is between $0.14-0.17$. The interpretation is that if my neighbors raise their price by on average $10 \%$ (weighted by their relative inverse distances), the own price will increase by $1.4-1.7 \%$. Thus, the effect is relatively modest but still economically significant. It is statistically significant in all specifications except for the mixed model, which is likely due to the identification issues discussed above.

The SAR model is only relevant in case of no omitted variables, otherwise the durbin model is more appropriate. Maximum likelihood tests show that the durbin model is the preferred choice. ${ }^{12}$ Robustness tests using alternative definitions of the weight matrix in the durbin model (i.e. varying the number of neighbors between 5 and 15) are coherent; all estimates of $\hat{\rho}$ are significant on the $5 \%$-level and the magnitude ranges between 0.12-0.14. Full estimation results are available on request. The robustness test using the small sample (i.e. removing all municipalities that engage in some type of operational cooperation) confirms that the effect is statistically significant, although the magnitude is smaller. Complete results from the small sample estimation are presented in table A2.

The IV-estimate of $\hat{\rho}$ is 0.31 , i.e. around twice the magnitude compared to the maximum likelihood estimators. As a comparison, the OLS estimate is 0.29 and significant on the $5 \%$ level. Since the OLS estimate is biased upwards by construction, the spatial lag of the dependent variable has been excluded from table 2 in order to avoid misspecification, and any stronger effect should be questioned. Consequently, there are reasons to doubt the exogeneity assumption. A plausible explanation is that utilities differ in how quickly they respond to persistent shocks: If my neighbors respond to a common shock before I do, my price today will be more correlated with neighbors' past prices than their prices today. Hence, the exogeneity assumption will be violated. Another plausible reason is that price mimicking is not only simultaneous, but also backward looking. Therefore, the IV-estimates should be interpreted with care. $^{13}$

\footnotetext{
${ }^{12}$ Since the SAR model is nested within the durbin model, the procedure is to test the null hypothesis $\hat{\gamma}=0$, i.e. that all coefficients on the spatial lags of the independent variables are zero. This test shows that we cannot reject the presence of omitted variables (the p-value is 0.07 , indicating that there is only a trivial probability that the spatial lags of the independent variables are zero) A similar test can be made for the mixed model, since it nests both the SAR and the SEM models. When testing the restriction $\hat{\rho}=0$, the p-value is 0.25 , and when testing the restriction $\hat{\lambda}=0$ the p-value is 0.89 . This indicates that there is a much stronger case for spatial dependence than spatial error correlation, and therefore the SEM model is rejected.

${ }^{13}$ Theoretically, the latter issue should be attenuated by instead instrumenting using the second time-lag. However, since this actually increases $\hat{\rho}$ (the magnitude is 0.47 and is significant on the $5 \%$
} 
The covariate that has the strongest impact on price is population, with a statistically significant coefficient of -0.3 in four of the six specifications. The interpretation is that a ten percent increase in the population is associated with a three percent decrease in the water price. Given that population is a good proxy for the amount of delivered water, this indicates returns to scale in water purification. This is not surprising, since the size of the utilities traditionally has been determined by municipal boundaries rather than returns to scale. In line with this result, Mizutani and Urakami (2001) find that the optimal size for a size of a water supply organization would be one supplying a population of approximately 800000 , which is well above the 30000 average population in a Swedish municipality. Although their estimate is based on Japanese data, results are coherent. The reason why the number of houses has no impact on the price could be due to the connection fee, which in theory should finance the cost of connecting new properties to the network.

Given that the utilities do not fully comply with the regulatory framework, some of the variables relating to the financial situation of the municipalities have the expected signs: An extra income in the form of a government grant leads to a statistically significant lower price, even if the elasticity is less than one percent. The positive effect of the tax rate (ranging between 0.36-0.44) indicates that increased prices could be used as complements to increased taxes, although the effect is not statistically significant. By contrast, extraordinary income as well as the municipality surplus appears to have a positive effect on the price (although the effect of the surplus is insignificant), while the expected effect is the opposite if financial distress is remedied through higher prices. Both these coefficients are small, with elasticities below one percent. However, if utility profits subsidize the general budget these coefficients will suffer from a positive simultaneity bias. Finally, political rule does not have any economically or statistically significant effect on prices. Since the variables relating to the financial situation of the municipalities only show modest effects on the price, it is not surprising that basic results are similar when estimating the models when only controlling for cost factors. These results are presented in table A3.

When estimating the durbin model excluding municipalities in which the incumbent coalition's electoral support was $50 \pm 3 \%$ (which removes $30 \%$ of the sample), $\hat{\rho}$ is 0.15 (significant on the $5 \%$ level). Thus, it does not appear that a politically stable electorate attenuates yardstick competition. Interpretations of this result are discussed further in section six below.

\section{Results from the cross-sectional estimates}

Results from the main specification are presented in table 3 .

[Table 3 about here]

level), this solution is not adequate. Another option would have been to instrument using neighbors ' characteristics. However, this also resulted in higher estimates of $\hat{\rho}$ than the OLS estimate. Full estimation results are available on request. 
Estimates of $\hat{\rho}$ are consistently higher than for the panel estimates, and ranges between $0.22-0.27$ (all estimates are significant on the $10 \%$ level or lower). A likelihood ratio test shows that we cannot reject the SAR model in favor of the durbin model 14. Since several of the covariates have a statistically and economically significant effect on the dependent variable the mixed model is identified. Examining the mixed model coefficients, we can also conclude that there is only a trivial amount of spatial error correlation. The IV estimate of $\hat{\rho}$ is only marginally smaller than in the mixed model, which is comforting. In contrast to the panel estimates, there are no apparent reasons why the exogeneity assumption should be violated here.

Several of the covariates have a significant impact on the water price. The variable that has the strongest impact is capacity utilization, i.e. the amount of delivered water per meter pipeline. If the amount of delivered water increases ten percent, price drops almost two percent. This confirms results from the panel estimates, given that the "population" variable in the panel data was merely a proxy for the amount of delivered water. In this light, it is not surprising that the number of connected residents has a relatively modest effect on the price. The second most important cost factor is pipeline length per connected resident. The negative coefficient indicates returns to density in water provision, which has previously been discussed by e.g. Mizutani and Urakami (2001). The number of purification plants has a positive and significant impact on the price, indicating that it is more costly to supply a given amount of water using several plants. However, the effect is comparatively small. Investment cost also has the expected sign. Given that around half of the investments are financed by user fees (and the rest by connection fees), back-of-the-envelope calculations indicates a depreciation time of around 35 years, which seems reasonable. Finally, the mean wage for a civil servant has a positive effect, although the precision is low in most specifications.

Robustness results show that the spatial dependence is not isolated to municipalities that have interconnected networks. In fact, estimates were on average even higher in the small sample. Full results from the robustness test are presented in table A4. In sum, the cross-sectional estimates indicate an even stronger spatial dependence than the panel estimates. However, since the risk of misspecification is inherently larger when fixed effects are absent these results should be interpreted with care.

\section{A further discussion on underlying mechanisms and implications for efficiency}

Previous studies on strategic interactions between local governments have assumed that the policy maker is a local politician who maximizes votes rather than profits. However, the majority of decisions related to operation and pricing are presumably

\footnotetext{
${ }^{14}$ The p-value was 0.29 , showing that we cannot reject the null hypothesis that the spatial lags of the independent variables are zero.
} 
handled by managers directly. This notion is supported by the observation that spatial dependence is not attenuated in municipalities with a politically stable electorate: If politicians mimic their neighbors' policies in order to gain votes, they should be less inclined to do so in municipalities where small changes in electoral support does not matter for political power. Also, the covariates reflecting the financial situation of the municipalities only have a minor effect on pricing decisions. The view that utilities are largely independent entities is confirmed by Haraldsson (2013) in a recent government report about accounting standards of Swedish water utilities. He argues that "Due to weak external control and a lack of interest from politicians, the quality of financial accounting is largely dependent on the individual [utility] official's knowledge and ambitions" (p.6, freely translated from Swedish). While it is certainly possible to interpret politicians' disinterest as a general aversion towards external auditing, the fact remains that since utilities are not financed by tax revenues, politicians' incentives for keeping track of the utilities' budgets are reduced. Even if managers cannot be voted out of office directly, their job will be at stake if they are considered to run the utility inefficiently, or if consumers believe that utilities abuse their monopoly power. Consumers may exercise their power either by complaining to the local authorities directly, or to the Swedish Water Supply and Sewage Tribunal. Whether consumers are motivated by rational or behavioral reasons, a strategic response for managers is to set prices that conform to the prices of neighboring utilities.

Hitherto, we have assumed that price mimicking is explained by yardstick regulation alone, as opposed to resource flows. However, while it is true that water prices could be an important determinant for the location of water intensive industries, the main share of water used in industrial production in Sweden (94\%) are extracted from water sources owned by the companies themselves (Statistics-Sweden, 2013). Also, water intensive industries often negotiate prices directly with their local government, and the decision variable in this study concerns residential consumption exclusively. Regarding migration flows, it may be assumed that water prices affect the choice of living only on the margin: Water prices have a much smaller impact on the regular household's budget than other policies that differ between municipalities, such as local income tax rates.

Another topic that has been overlooked so far is implications for efficiency. While allocative efficiency should be more or less unaffected by yardstick competition due to a highly inelastic demand, there is presumably a positive effect on productive efficiency: One of the main rationales behind yardstick regulation is to incentivize firms to reduce costs, since the prices that firms receives are independent from their own costs. A conjecture is then that informal yardstick competition induces a similar mechanism, since the firms that are able to cut costs more than their neighbors will incur a profit. However, an important feature of formal yardstick regulation is that firms have identical cost structures, or that the regulator is able to distinguish differences in cost structures across regions. In the present setting, benchmarks are 
instead rather arbitrary: The higher cost a municipality has relative its neighbors, the more managers will be incentivized to reduce costs (if managers' utility is concave in profits, this asymmetry will be strengthened). In sum, even though informal yardstick regulation is a less precise mechanism than formal yardstick regulation, basic economic reasoning suggests that the presence of informal yardstick competition has a positive effect on productive efficiency.

\section{Conclusion}

This study provides the first empirical test of spatial interactions in the pricing decisions of regulated utilities. Since publicly owned water utilities in Sweden are governed by a c-o-s regulation, prices in neighboring municipalities should not affect the own price other than through spatially correlated cost factors. In contrast, spatial dependence is pronounced. This behavior can be explained in terms of an informal yardstick competition: When consumers use neighboring utilities' prices as benchmarks for costs or as behaviorally based reference points, utilities will face the risk of consumer complaints if deviating too much from neighbors' prices. Just as under formal yardstick regulation, there are incentives to reduce costs: If a utility is able to cut costs relative to its neighbors, only a part of the cost reduction needs to be translated into a lower price. Thus, basic economic reasoning suggests that the presence of informal yardstick competition has a positive effect on productive efficiency.

Further, spatial dependence is not attenuated in municipalities with a politically stable electorate. In coherence with this result, prices only appear to be marginally affected by the overall financial situation of the municipality, suggesting that managers' decisions rather than political influence is the main driving mechanism behind the result.

Using a spatial durbin model with fixed effects, the elasticity of the own- relative to neighbors' average price is estimated to be 0.14. Cross-sectional data is examined, using more detailed data on the technical characteristics of the utilities. These estimates point towards an even stronger spatial dependence. However, due to the increased risk of misspecification in the absence of fixed effects, results from the cross-sectional sample should be interpreted with care. 


\section{Figures and tables}

Figure 1: Trends in water prices for a typical household.

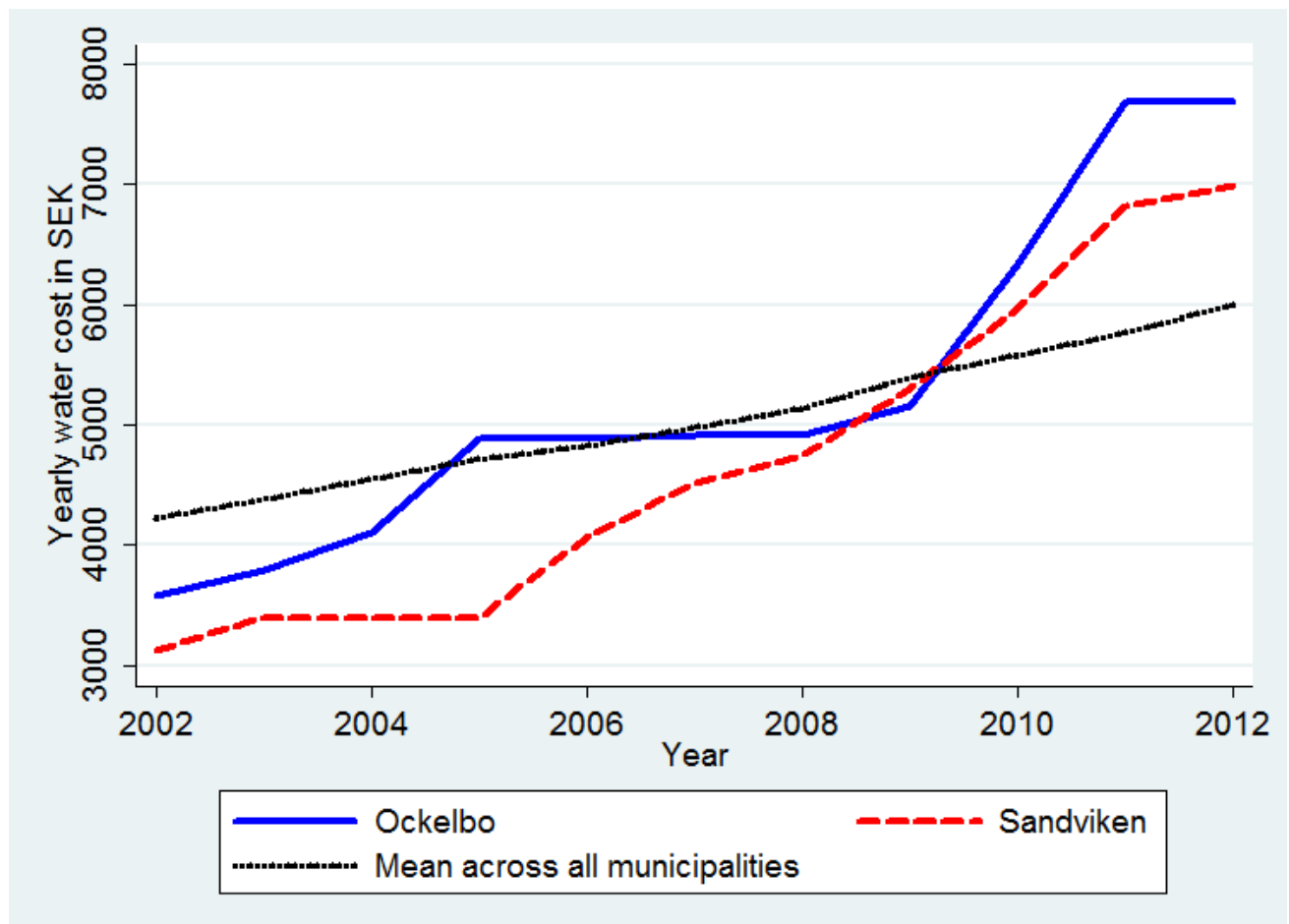

Note: This table shows time trends in the water price for the two neighboring municipalities Ockelbo (solid blue line) and Sandviken (dashed red line). It is expressed as the total cost (i.e. fixed plus variable cost) in SEK for a typical stand-alone house consuming $150 \mathrm{~m}^{3}$ per year. The dotted black line shows the mean total cost across all 288 municipalities. 
Table 1. Descriptive statistics.

\begin{tabular}{lccccc}
\hline \multicolumn{1}{c}{ Variable } & Mean & Std. Dev. & Min. & Max. & Obs. \\
\hline Water price & 5050 & 1281 & 2015 & 9700 & 3168 \\
Single-family houses & 6913 & 6180 & 517 & 54840 & 3168 \\
Apartment houses & 8398 & 27303 & 151 & 405452 & 3168 \\
Extraordinary income-cost & 3168 & 39130 & -3900 & -1071406 & 1341354 \\
Government grant & 190278 & 295530 & -1199547 & 3975628 & 3168 \\
Tax rate & 21 & 1 & 17 & 33 & 3168 \\
Population & 31598 & 62128 & 2420 & 880008 & 3168 \\
Municipality surplus & 51897 & 303241 & -3756467 & 8722432 & 3168 \\
Purification plants & 15 & 13 & 0 & 71 & 243 \\
Pipeline length & 264 & 243 & 16 & 2157 & 243 \\
Capacity utilization & 8 & 7 & 0 & 62 & 243 \\
Connected residents & 30246 & 67445 & 1200 & 850100 & 243 \\
Investment & 12812 & 37272 & -9879 & 475000 & 243 \\
Wage & 21560 & 692 & 20100 & 24500 & 243 \\
Leftwing & 0.47 & 0.49 & 0 & 1 & 3168 \\
\hline
\end{tabular}

Note: This table shows descriptive statistics of each variable. For a detailed description of each variable, see table A1. 
Figure 2. Water price in 2004.

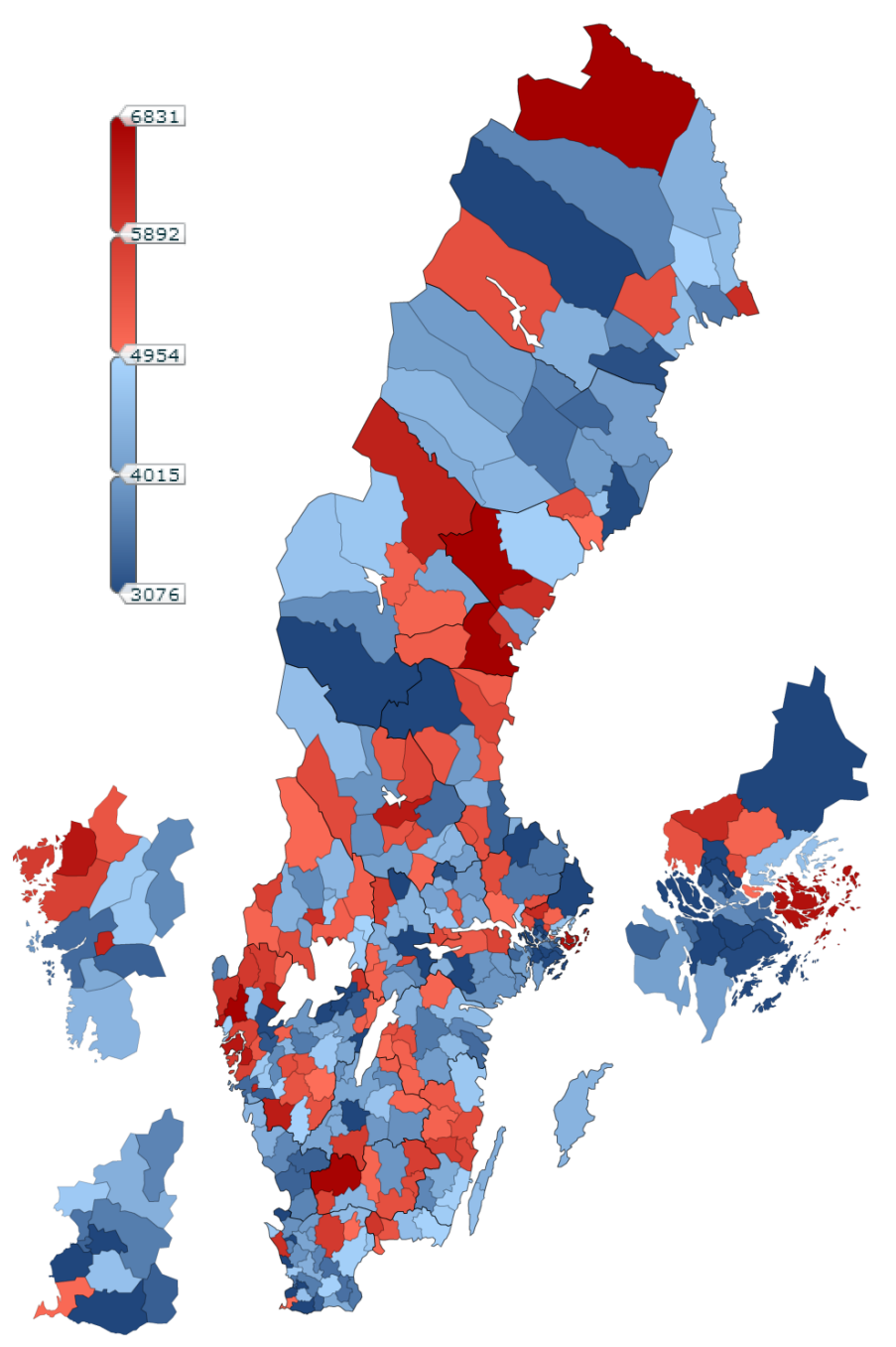

Note: This figure depicts the water price, expressed as the total cost (i.e. fixed plus variable cost) of water in 2004 for a typical stand-alone house consuming $150 \mathrm{~m}^{3}$ per year. The lowest cost is 3076 SEK, the highest cost is 6831 SEK and the median cost is 4954 SEK. If the municipality is red, it implies that the cost is above the median, and vice versa if the municipality is blue. 
Table 2. Panel model estimates. Dependent variable: Water price.

\begin{tabular}{|c|c|c|c|c|c|c|}
\hline & OLS & SAR & SEM & Mixed & Durbin & $\operatorname{SAR}(I V)$ \\
\hline$\hat{\rho}(\mathrm{W} *$ Water price $)$ & & $0.1745^{* * *}$ & & 0.1569 & $0.1438^{* * *}$ & $0.3051^{*}$ \\
\hline$\hat{\lambda}(\mathrm{W} *$ Error term $)$ & & & $0.1740^{* * *}$ & 0.0200 & & \\
\hline Apartment house & 0.0702 & 0.0596 & 0.0485 & 0.0587 & -0.0655 & 0.0495 \\
\hline Single-family house & 0.0103 & 0.0096 & 0.0090 & 0.0096 & -0.0019 & 0.0040 \\
\hline Population & $-0.3129^{* *}$ & $-0.2812^{* *}$ & $-0.2963^{* *}$ & $-0.2816^{* *}$ & -0.2175 & -0.1771 \\
\hline Tax rate & 0.3554 & 0.3658 & 0.3926 & 0.3674 & 0.4302 & 0.4351 \\
\hline Extra income-cost & $0.0033^{* * *}$ & $0.0028^{* * *}$ & $0.0023^{* * *}$ & $0.0028^{* * *}$ & $0.0032^{* * *}$ & -0.0003 \\
\hline Government grant & $-0.0075^{* * *}$ & $-0.0075^{* * *}$ & $-0.0075^{* * *}$ & $-0.0075^{* * *}$ & $-0.0074^{* * *}$ & $-0.0091^{* * *}$ \\
\hline Municipality surplus & 0.0009 & 0.0007 & 0.0004 & 0.0007 & 0.0007 & 0.0755 \\
\hline Leftwing & 0.0063 & 0.0058 & 0.0053 & 0.0058 & 0.0045 & 0.0056 \\
\hline $\mathrm{W} *$ Apartment house & & & & & $0.2892^{* * *}$ & \\
\hline $\mathrm{W} *$ Single-family house & & & & & 0.0377 & \\
\hline $\mathrm{W} *$ Population & & & & & -0.2210 & \\
\hline $\mathrm{W} *$ Tax rate & & & & & -0.3771 & \\
\hline $\mathrm{W} *$ Extra income-cost & & & & & $0.018^{* *}$ & \\
\hline $\mathrm{W} *$ Government grant & & & & & 0.0022 & \\
\hline $\mathrm{W} *$ Profit & & & & & 0.0047 & \\
\hline $\mathrm{W} *$ Leftwing & & & & & 0.0128 & \\
\hline Log lik. & & 5333.9852 & 5333.0770 & 5333.9885 & 5355.6460 & \\
\hline Observations & 3168 & 3168 & 3168 & 3168 & 3168 & 2880 \\
\hline
\end{tabular}

${ }^{*} p<.10,{ }^{* *} p<0.05,{ }^{* * *} p<0.01$

Note: Panel model estimates using data from 2002-2012. All variables have been logged. The dependent variable is water price. Year- and municipality fixed effects are included in all models. Standard errors are clusterd on the municipality level. In the IV model, the first time-lag of $\mathrm{W}^{*}$ Water is used as an instrument for $\mathrm{W}^{*}$ Water price. 
Table 3: Cross-sectional estimates. Dependent variable: Water price.

\begin{tabular}{|c|c|c|c|c|c|c|}
\hline & OLS & SAR & SEM & Mixed & Durbin & SAR(IV) \\
\hline$\hat{\rho}\left(\mathrm{W}^{*}\right.$ Water price $)$ & & $0.267^{* * *}$ & & $0.2460^{*}$ & $0.234^{* *}$ & $0.225^{*}$ \\
\hline$\hat{\lambda}(\mathrm{W} *$ Error term $)$ & & & $0.291^{* * *}$ & 0.0799 & & \\
\hline Purification plants & $0.0351^{* * *}$ & $0.0280^{* *}$ & $0.0388^{* * *}$ & $0.0298^{* *}$ & $0.0335^{* *}$ & $0.030^{* *}$ \\
\hline Pipeline length & $-0.1339^{* * *}$ & $-0.1246^{* * *}$ & $-0.1084^{* * *}$ & $-0.1219^{* * *}$ & $-0.1048^{* * *}$ & $-0.126^{* * *}$ \\
\hline Capacity utilization & $-0.1975^{* * *}$ & $-0.1859^{* * *}$ & $-0.1669^{* * *}$ & $-0.1827^{* * *}$ & $-0.1718^{* * *}$ & $-0.187^{* * *}$ \\
\hline Connected residents & $-0.0923^{* * *}$ & $-0.0975^{* * *}$ & $-0.0999^{* * *}$ & $-0.0983^{* * *}$ & $-0.0915^{* * *}$ & $-0.098^{* * *}$ \\
\hline Investment & $0.0142^{* *}$ & $0.0134^{* * *}$ & $0.0118^{* *}$ & $0.0132^{* *}$ & $0.0126^{* *}$ & $0.013^{* *}$ \\
\hline Single-family houses & 0.0325 & 0.0208 & 0.0186 & 0.0204 & 0.0076 & 0.024 \\
\hline Wage & 0.3107 & $0.6653^{* *}$ & 0.3774 & $0.6271^{*}$ & 0.5851 & 0.563 \\
\hline $\mathrm{W} *$ Purification plants & & & & & -0.0226 & \\
\hline $\mathrm{W} *$ Pipeline length & & & & & -0.1421 & \\
\hline $\mathrm{W} *$ Capacity utilization & & & & & -0.1869 & \\
\hline $\mathrm{W} *$ Connected residents & & & & & 0.1554 & \\
\hline $\mathrm{W} *$ Investment & & & & & 0.0108 & \\
\hline $\mathrm{W} *$ Single-family houses & & & & & 0.0138 & \\
\hline $\mathrm{W} *$ Wage & & & & & -0.3565 & \\
\hline Log lik. & & 167.6996 & 165.2687 & 167.7824 & 172.1966 & \\
\hline Observations & 243 & 243 & 243 & 243 & 243 & 243 \\
\hline
\end{tabular}

${ }^{*} p<.10,{ }^{* *} p<0.05,{ }^{* * *} p<0.01$

Note: Cross-sectional estimates using data from 2004. All variables have been logged. The dependent variable is water price. 
9 Appendix

Table A1. Detailed description of the variables.

\begin{tabular}{|c|c|c|c|}
\hline Variable & Description & Measurement & Source \\
\hline Water price & $\begin{array}{l}\text { Yearly cost of water for a } \\
\text { stand-alone house with } \\
\text { one family consuming } \\
150 \mathrm{~m}^{3} \text { per year }\end{array}$ & SEK & VASS \\
\hline Single-family houses & Nr. of single-family houses & - & SCB \\
\hline Extraordinary cost & $\begin{array}{l}\text { Extraordinary cost for the } \\
\text { municipality (from the } \\
\text { municipalities' income statements) }\end{array}$ & SEK (thousands) & SCB \\
\hline Extraordinary income & $\begin{array}{l}\text { Extraordinary income for the } \\
\text { municipality (from the } \\
\text { municipalities' income statements) }\end{array}$ & SEK (thousands) & SCB \\
\hline Government grant & $\begin{array}{l}\text { Transferred money from the } \\
\text { national government to the municipality }\end{array}$ & SEK (thousands) & SCB \\
\hline Tax rate & $\begin{array}{l}\text { Municipality income tax rate } \\
\text { (always proportional) }\end{array}$ & Percentage & SCB \\
\hline Population & Nr. of residents & - & SCB \\
\hline Municipality surplus & $\begin{array}{l}\text { Total surplus of the municipality (from the } \\
\text { municipalities' income statements) }\end{array}$ & SEK (thousands) & SCB \\
\hline Purification plants & $\begin{array}{l}\text { Total nr. of purification plants (both for } \\
\text { wastewater, ground water and surface water) }\end{array}$ & - & VASS \\
\hline Wage & Mean monthly wage for a public servant & SEK & SCB \\
\hline Leftwing & $\begin{array}{l}\text { Takes the value one if Socialdemokraterna or } \\
\text { Vänsterpartiet are members of the ruling coalition }\end{array}$ & Dummy & SKL \\
\hline
\end{tabular}

Note: VASS is Vattentjänstbranschens statistisksystem (data has been downloaded from www.vass-statistik.se) SCB is Statistics Sweden (data has been downloaded from www.scb.se). SKL is Sveriges Kommuner och Landsting (data has been downloaded from www.skl.se). 
Figure A1. Histogram of the water price in each municipality during 2002-2012.

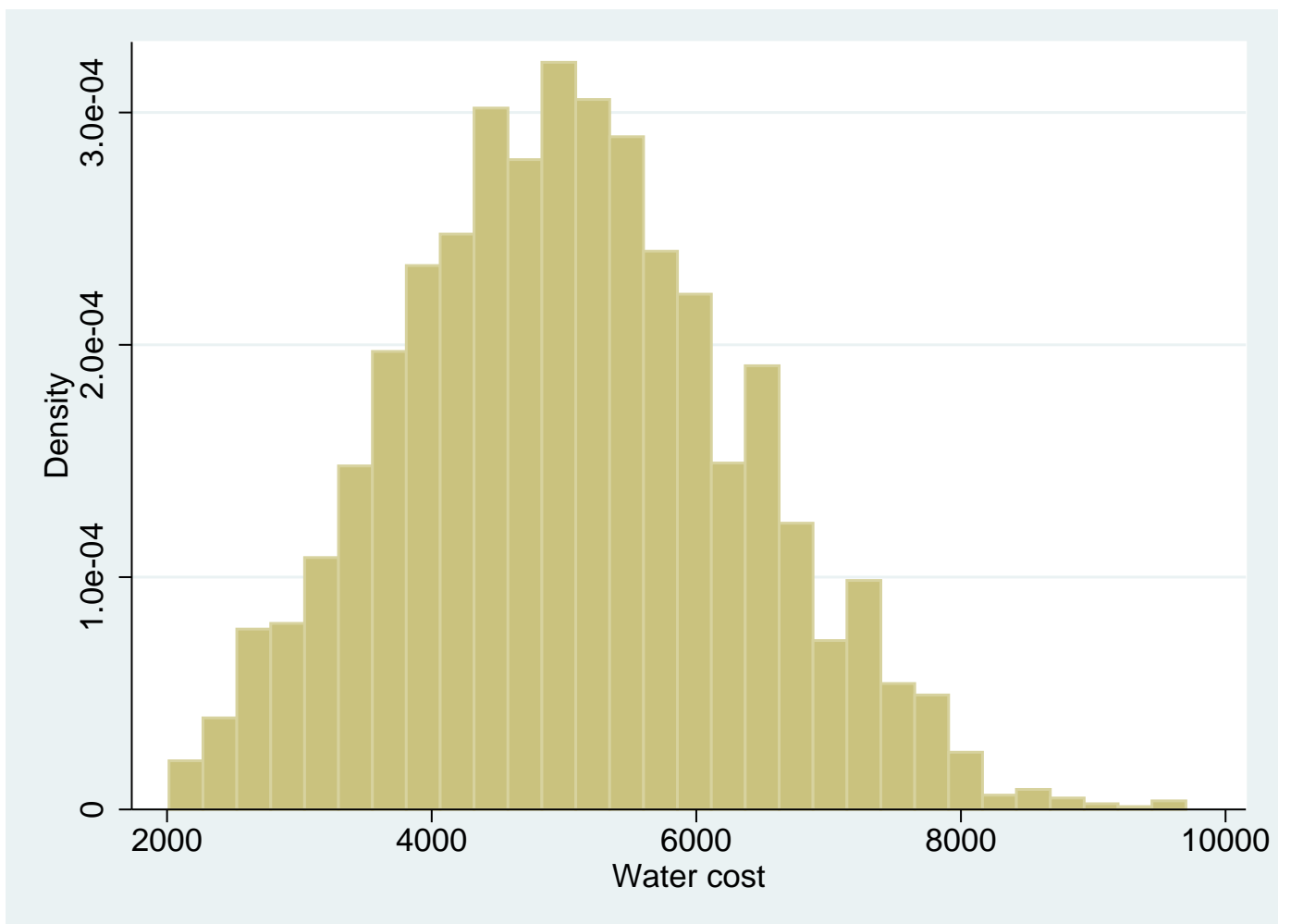

Note: This figure shows a histogram of the water price for the whole sample, i.e. 3168 observations during 2002-2012. 
Table A2. Panel estimates, including only the utilities that did not engage in cooperation with other utilities. Dependent variable: Water price.

\begin{tabular}{|c|c|c|c|c|c|c|}
\hline & OLS & SAR & SEM & Mixed & Durbin & $\mathrm{SAR}(\mathrm{IV})$ \\
\hline$\hat{\rho}\left(\mathrm{W}^{*}\right.$ Water price $)$ & & $0.1132^{*}$ & & 0.0978 & $0.1014^{*}$ & $0.305^{*}$ \\
\hline$\hat{\lambda}\left(\mathrm{W}^{*}\right.$ Error term $)$ & & & $0.1125^{*}$ & 0.0162 & & \\
\hline Apartment house & 0.0834 & 0.0768 & 0.0732 & 0.0762 & -0.0055 & 0.0657 \\
\hline Single-family house & 0.0485 & 0.0457 & 0.0457 & 0.0457 & 0.0397 & 0.0371 \\
\hline Population & $-0.3652^{* *}$ & $-0.3469^{* *}$ & $-0.3462^{* *}$ & $-0.3468^{* *}$ & -0.2199 & -0.2516 \\
\hline Tax rate & 0.3965 & 0.4189 & 0.4436 & 0.4211 & $0.6212^{*}$ & 0.4507 \\
\hline Extra income-cost & 0.0298 & 0.0293 & 0.0284 & 0.0294 & 0.0351 & -0.0003 \\
\hline Government grant & 0.0420 & 0.0367 & 0.0348 & 0.0366 & 0.0112 & 0.0275 \\
\hline Municipality surplus & 0.0338 & 0.0333 & 0.0341 & 0.0335 & 0.0205 & 0.0755 \\
\hline Leftwing & 0.0049 & 0.0045 & 0.0043 & 0.0045 & 0.0032 & 0.0011 \\
\hline $\mathrm{W} *$ Apartment house & & & & & 0.1578 & \\
\hline $\mathrm{W} *$ Single-family house & & & & & 0.0281 & \\
\hline $\mathrm{W}^{*}$ Population & & & & & -0.3029 & \\
\hline $\mathrm{W} *$ Tax rate & & & & & -0.9633 & \\
\hline $\mathrm{W} *$ Extra income-cost & & & & & 0.1587 & \\
\hline $\mathrm{W} *$ Government grant & & & & & -0.0972 & \\
\hline $\mathrm{W} *$ Profit & & & & & 0.0047 & \\
\hline $\mathrm{W} *$ Leftwing & & & & & 0.0130 & \\
\hline Log lik. & & 3970.0697 & 3969.9000 & 3970.0854 & 3977.4918 & \\
\hline Observations & 2299 & 2299 & 2299 & 2299 & 2299 & 2090 \\
\hline
\end{tabular}

${ }^{*} p<.10,{ }^{* *} p<0.05,{ }^{* * *} p<0.01$

Note: Panel model estimates using data from 2002-2012. All variables have been logged. The dependent variable is water price. Year- and municipality fixed effects are included in all models. Standard errors are clusterd on the municipality level. In the IV model, the first time-lag of $\mathrm{W}^{*}$ Water is used as an instrument for $\mathrm{W}^{*}$ Water price. 
Table A3. Panel estimates, including only cost factors as covariates. Dependent variable: Water price.

\begin{tabular}{|c|c|c|c|c|c|c|}
\hline & OLS & SAR & SEM & Mixed & Durbin & $\mathrm{SAR}(\mathrm{IV})$ \\
\hline$\hat{\rho}(\mathrm{W} *$ Water price $)$ & & $0.1778^{* * *}$ & & 0.1486 & $0.1593^{* * *}$ & $0.312^{* *}$ \\
\hline$\hat{\lambda}(\mathrm{W} *$ Error term $)$ & & & $0.1778^{* * *}$ & 0.0338 & & \\
\hline Apartment houses & 0.0866 & 0.0732 & 0.0616 & 0.0709 & -0.0135 & 0.0722 \\
\hline Single-family houses & 0.0115 & 0.0102 & 0.0090 & 0.0098 & -0.0007 & 0.0363 \\
\hline Population & $-0.3808^{* * *}$ & $-0.3362^{* *}$ & $-0.3533^{* *}$ & $-0.3396^{* *}$ & $-0.2675^{*}$ & -0.2364 \\
\hline $\mathrm{W} *$ Apartment houses & & & & & $0.2630^{* *}$ & \\
\hline $\mathrm{W} *$ Single-family houses & & & & & 0.0501 & \\
\hline $\mathrm{W} *$ Population & & & & & -0.2647 & \\
\hline Log lik. & & 5317.9456 & 5317.1206 & 5317.9963 & 5329.2552 & 3728.9289 \\
\hline Observations & 3168 & 3168 & 3168 & 3168 & 3168 & 2880 \\
\hline
\end{tabular}

${ }^{*} p<.10,{ }^{* *} p<0.05,{ }^{* * *} p<0.01$

Note: Panel model estimates using data from 2002-2012. All variables have been logged. The dependent variable is water price. Year- and municipality fixed effects are included in all models. Standard errors are clusterd on the municipality level. In the IV model, two time-lags of $\mathrm{W}^{*}$ Water price are used as instruments for $\mathrm{W} *$ Water price. 
Table A4. Cross-sectional estimates, only including disconnected networks. Dependent variable: Water price.

\begin{tabular}{|c|c|c|c|c|c|c|}
\hline & OLS & SAR & SEM & Mixed & Durbin & SAR(IV) \\
\hline$\hat{\rho}(\mathrm{W} *$ Water price $)$ & & $0.3951^{* * *}$ & & 0.2749 & $0.3866^{* * *}$ & $0.47^{* * *}$ \\
\hline$\hat{\lambda}(\mathrm{W} *$ Error term $)$ & & & $0.4269^{* * *}$ & 0.1764 & & \\
\hline Purification plants & 0.0218 & 0.0199 & 0.0179 & 0.0193 & 0.0184 & 0.016 \\
\hline Pipeline length & $-0.2010^{* * *}$ & $-0.1652^{* * *}$ & $-0.1684^{* * *}$ & $-0.1675^{* * *}$ & $-0.1766^{* * *}$ & $-0.159^{* * *}$ \\
\hline Capacity utilization & $-0.2109^{* * *}$ & $-0.1836^{* * *}$ & $-0.1853^{* * *}$ & $-0.1860^{* * *}$ & $-0.1925^{* * *}$ & $-0.180^{* * *}$ \\
\hline Connected residents & 0.0456 & 0.0527 & 0.0362 & 0.0483 & 0.0512 & $-0.106^{* * *}$ \\
\hline Investment & $0.0142^{*}$ & $0.0127^{*}$ & 0.0114 & $0.0124^{*}$ & $0.0145^{*}$ & $0.014^{* * *}$ \\
\hline Single-family houses & $0.1062^{*}$ & 0.0561 & 0.0883 & 0.0661 & 0.0734 & 0.051 \\
\hline Wage & 0.1172 & 0.3691 & 0.4119 & 0.3796 & 0.3778 & 0.350 \\
\hline $\mathrm{W} *$ Purification plants & & & & & 0.0592 & \\
\hline $\mathrm{W} *$ Pipeline Length & & & & & -0.0482 & \\
\hline $\mathrm{W} *$ Capacity utilization & & & & & 0.0103 & \\
\hline $\mathrm{W} *$ Connected residents & & & & & 0.1009 & \\
\hline $\mathrm{W} *$ Investment & & & & & 0.0055 & \\
\hline $\mathrm{W} *$ Single-family houses & & & & & -0.1229 & \\
\hline $\mathrm{W} *$ Wage & & & & & -1.0121 & \\
\hline Sq. Corr. & & 0.2871 & 0.2659 & 0.2843 & 0.3034 & \\
\hline Var. Ratio & & 0.2602 & 0.2091 & 0.2502 & 0.2624 & \\
\hline Log lik. & 91.6738 & 98.3900 & 98.0487 & 98.4356 & 99.4846 & \\
\hline Observations & 138 & 138 & 138 & 138 & 138 & 138 \\
\hline
\end{tabular}

${ }^{*} p<.10,{ }^{* *} p<0.05,{ }^{* * *} p<0.01$

Note: Cross-sectional estimates using data from 2004. All variables have been logged. The dependent variable is water price. Only municipalities that did not buy or sell water during 2004 have been included in the regression. 


\section{References}

Anselin, L. (1980): "Estimation Methods for Spatial Autoregressive Structures," Ph.D. thesis, Regional Science Dissertation and Monograph Series nr 8. Ithaca: Cornell University.

Azomahou, T., and A. Lahatte (2000): "On the Inconsistency of the Ordinary Least Squares Estimator for Spatial Autoregressive Processes," Working Papers of BETA 2000-12, Bureau d'Economie Théorique et Appliquée, UDS, Strasbourg.

Belotti, F., G. Hughes, and A. P. Mortari (2013): "xsmle-A Command to Estimate Spatial Panel Models in Stata," German Stata User Group Meetings 2013 09, Stata Users Group.

Besley, T., and A. Case (1995): "Incumbent Behavior: Vote-Seeking, Tax-Setting, and Yardstick Competition," American Economic Review, 85(1), 25-45.

Bivand, R., and S. Szymanski (1997): "Spatial dependence through local yardstick competition:: theory and testing," Economics Letters, 55(2), 257-265.

Brueckner, J. K. (2003): "Strategic Interaction Among Governments: An Overview of Empirical Studies," International Regional Science Review, 26(2), 175-188.

Buettner, T. (2001): "Local business taxation and competition for capital: the choice of the tax rate," Regional Science and Urban Economics, 31, 215 - 245, <ce:title>Fiscal Competition and Federalism in Europe $</$ ce:title $>$.

Drukker, D. M., I. Prucha, and R. Raciborski (2013): "Maximum likelihood and generalized spatial twostage least-squares estimators for a spatial-autoregressive model with spatial-autoregressive disturbances," Stata Journal, 13(2), 221-241.

Figlio, D. N., V. W. Kolpin, and W. E. Reid (1999): "Do States Play Welfare Games?," Journal of Urban Economics, 46(3), 437-454.

GeYs, B. (2006): "Looking across borders: A test of spatial policy interdependence using local government efficiency ratings," Journal of Urban Economics, 60(3), 443-462.

Green, J. R., and N. L. Stokey (1983): "A Comparison of Tournaments and Contracts," Journal of Political Economy, 91(3), pp. 349-364.

HaRALDSSOn, M. (2013): Särredovisning inom VA-branschen, vol. 2013-21. Svenskt Vatten Utveckling.

Holmstrom, B. (1982): "Moral Hazard in Teams," Bell Journal of Economics, 13(2), 324-340.

Jacobs, J., J. Ligthart, and H. VRijburg (2010): "Consumption tax competition among governments: Evidence from the United States," International Tax and Public Finance, 17(3), 271-294.

Kanbur, R., and M. Keen (1993): "Jeux Sans Frontieres: Tax Competition and Tax Coordination When Countries Differ in Size," American Economic Review, 83(4), 877-92. 
Kelejian, H. H., and I. R. Prucha (1998): "A Generalized Spatial Two-Stage Least Squares Procedure for Estimating a Spatial Autoregressive Model with Autoregressive Disturbances," The Journal of Real Estate Finance and Economics, 17(1), 99-121.

Klien, M. (2012): "Institutional and Political Aspects of Public Infrastructure Provision," Discussion Paper EPPP DP No. 2012-04, Chaire EPPP, Sorbonne Business School.

KonKURRENSVERKET (2013): Inför prisregleringen av fjärrvärme. Konkurrensverket, Uppdragsforskningsrapport 2013:1.

Laffont, J. J., and J. Tirole (1993): "A Theory of Incentives in Regulation and Procurement," MIT Press.

LeSage, J., and R. Pace (2009): Introduction to Spatial Econometrics, Statistics: a Series of Textbooks and Monographs. C R C Press LLC.

Mintz, J., And H. Tulkens (1986): "Commodity tax competition between member states of a federation: equilibrium and efficiency," Journal of Public Economics, 29(2), 133-172.

Mizutani, F., and T. Urakami (2001): "articles: Identifying network density and scale economies for Japanese water supply organizations," Papers in Regional Science, 80(2), 211-230.

Moran, P. A. P. (1950): "Notes on Continuous Stochastic Phenomena," Biometrika, 37(1/2), pp. 17-23.

Revelli, F. (2005): "On Spatial Public Finance Empirics," International Tax and Public Finance, 12(4), $475-492$.

(2006): "Performance rating and yardstick competition in social service provision," Journal of Public Economics, 90(3), 459-475.

Revelli, F., And P. Tovmo (2007): "Revealed yardstick competition: Local government efficiency patterns in Norway," Journal of Urban Economics, 62(1), 121 - 134.

SCS (2013): Water and Sewage Act. Swedish Code of Statutes 2006:412.

Söderberg, M., and M. Tanaka (2012): "Spatial price homogeneity as a mechanism to reduce the threat of regulatory intervention in locally monopolistic sectors," Working Papers hal-00659458, HAL.

Shleifer, A. (1985): "A Theory of Yardstick Competition," RAND Journal of Economics, 16(3), 319-327.

SKL (2013): "Sveriges Kommuner och Landsting," www.skl.se.

Sole Olle, A. (2003): "Electoral accountability and tax mimicking: the effects of electoral margins, coalition government, and ideology," European Journal of Political Economy, 19(4), 685-713.

Statistics-Sweden (2013): Official records of Swedish statistics. Statistics Sweden, www.scb.se.

Svenskt-Vatten (2005): Fakta om vatten och avlopp, brochure. Svenskt Vatten.

SWSST (2013):. The Swedish Water Supply and Sewage Tribunal, http://www.vanamnden.se/1avgoranden2007/default.asp. 
Thaler, R. (1985): "Mental Accounting and Consumer Choice," Marketing Science, 4(3), pp. 199-214.

Tiebout, C. M. (1956): "A Pure Theory of Local Expenditures," Journal of Political Economy, 64, 416. 